\section{Commentary: Lung transplant: No support is best}

\author{
Stephanie H. Chang, MD, ${ }^{\mathrm{a}}$ and \\ Matthew C. Henn, MD ${ }^{b}$
}

The optimal intraoperative support for lung transplant remains undetermined. For patients who are able to tolerate single-lung ventilation with no significant pulmonary hypertension, lung transplant (single or double) may be performed without any extracorporeal life support. For patients requiring extracorporeal life support, both cardiopulmonary bypass (CPB) or extracorporeal membrane oxygenation (ECMO) are options. Single-center studies have compared CPB versus ECMO and have demonstrated decreased mortality, blood use, and primary graft dysfunction (PGD) with ECMO support, ${ }^{1}$ although other studies have shown excellent outcomes with CPB support. ${ }^{2}$ Other single-center studies have shown decreased PGD in patients supported with intraoperative venoarterial ECMO versus off-pump. ${ }^{3}$ Overall, the data remain limited by retrospective singleinstitution studies with no consensus regarding the ideal intraoperative support for lung transplant.

Loor and colleagues ${ }^{4}$ presents a registry analysis evaluating 852 lung transplants from 8 institutions, with 422 $(50 \%)$ off-pump, 273 (32\%) ECMO, and 157 (18\%) bypass. The primary end point was PGD grade 3 , with a PGD 3 rate of $12.1 \%$ with off-pump, $28.9 \%$ of ECMO, and $42.7 \%$ of patients who received CPB. The data also demonstrated that the off-pump cohort had the lowest mortality, reintubation, tracheostomy, postoperative ECMO requirement, and length of stay. In addition, 1-year survival was $91 \%$ for the off-pump group versus $84 \%$ in the ECMO group and $84 \%$ in the CPB group.

\footnotetext{
From the ${ }^{\mathrm{a}}$ Department of Cardiothoracic Surgery, New York University Langone Health, New York, NY; and ${ }^{\mathrm{b}}$ Division of Cardiac Surgery, Department of Surgery, Ohio State University Wexner Medical Center, Columbus, Ohio.

Disclosures: The authors reported no conflicts of interest.

The Journal policy requires editors and reviewers to disclose conflicts of interest and to decline handling or reviewing manuscripts for which they may have a conflict of interest. The editors and reviewers of this article have no conflicts of interest.

Received for publication Nov 21, 2021; revisions received Nov 21, 2021; accepted for publication Nov 22, 2021; available ahead of print Nov 25, 2021.

Address for reprints: Stephanie H. Chang, MD, Division of Thoracic Surgery, Department of Cardiothoracic Surgery, New York University Langone Health, 530 First Ave, Suite 9V, New York, NY 10016 (E-mail: stephanie.chang@nyulangone.org). J Thorac Cardiovasc Surg 2022;164:1362-3 0022-5223/\$36.00

Copyright $\Subset 2021$ Published by Elsevier Inc. on behalf of The American Association for Thoracic Surgery

https://doi.org/10.1016/j.jtcvs.2021.11.050
}

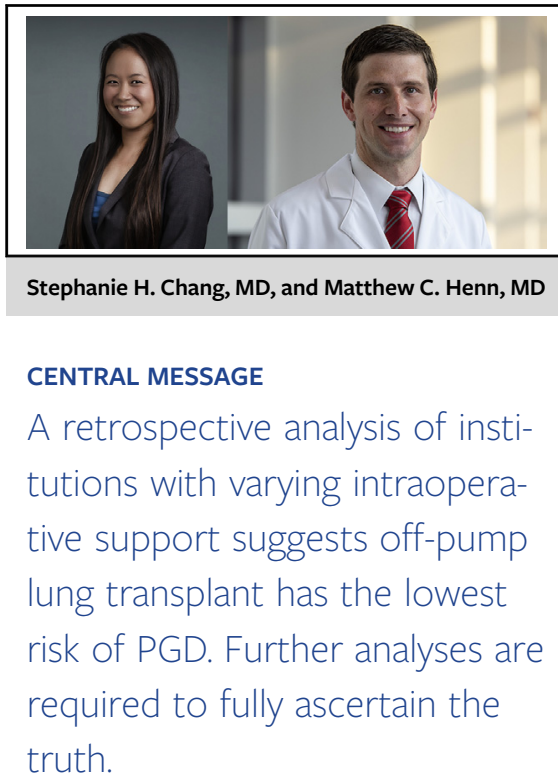

While this study shows a PGD 3 odds ratio of 4.24 in CPB versus off-pump, 2.24 in ECMO versus off-pump, and 1.89 in CPB versus ECMO, there are some factors that should be taken into account. First, the centers all varied with regard to institutional practice, which creates significant selection bias. The rate of CPB use ranged from $0 \%$ to $67 \%$, whereas off-pump ranged from $0 \%$ to $79 \%$ for off-pump use. This may be related to varying surgical approach-some centers used an anterior thoracotomy/clamshell approach, whereas others used a sternotomy (which often requires CPB). Blood transfusion requirement, which is likely greater in the CPB group and can be associated with development of PGD, ${ }^{5}$ was also not measured in this study. In addition, the recipient demographics are very different, with a statistically significant greater rate of obstructive disease, lower mean pulmonary artery pressure, decreased preoperative hospitalization, and no preoperative ECMO use in the offpump group. Each of those factors can play a role in the development of PGD.

While this study is interesting, the outcomes are still hampered by inherent selection bias. For many of these patients who were placed on ECMO or CPB, the patient may not have been a candidate for off-pump transplant. A subset analysis comparing modes of support and rates of PGD 3 for patients who would tolerate off-pump transplant including those with no significant hypoxia (such as oxygen requirement $\leq 6$ ), no severe pulmonary hypertension, and who are not hospitalized preoperatively would be helpful. Further, prospective evaluation in this patient population 
would be ideal. While these data would be helpful for transplant surgeons to decide optimal mode of support, most surgeons would agree that in patients who can tolerate it, no support is best.

\section{References}

1. Machuca TN, Collaud S, Mercier O, Cheung M, Cunningham B, Kim SJ, et al. Outcomes of intraoperative extracorporeal membrane oxygenation versus cardiopulmonary bypass for lung transplantation. J Thorac Cardiovasc Surg. 2015;149: 1152-7.
2. Taka H, Miyoshi K, Kurosaki T, Douguchi T, Itoh H, Sugimoto S, et al. Lung transplantation via cardiopulmonary bypass: excellent survival outcomes from extended criteria donors. Gen Thorac Cardiovasc Surg. 2019;67:624-32.

3. Hoetznecker K, Schwarz S, Muckenhuber M, Benazzo A, Frommlet F, Schweiger $\mathrm{T}$, et al. Intraoperative extracorporeal membrane oxygenation and the possibility of postoperative prolongation improve survival in bilateral lung transplant. J Thorac Cardiovasc Surg. 2017; 155:2193-206.

4. Loor G, Huddleston S, Hartwig M, Bottiger B, Daoud D, Wei Q, et al. Effect of mode of intraoperative support on primary graft dysfunction after lung transplant. J Thorac Cardiovasc Surg. 2022;164:1351-61.e4.

5. Diamond JM, Lee JC, Kawut SM, Shah RJ, Russell Localio A, Bellamy SL, et al Clinical risk factors for primary graft dysfunction after lung transplantation. Am J Respir Crit Care Med. 2013;187:527-34.
See Article page 1351.

\section{Commentary: Why a routine venoarterial extracorporeal membrane oxygenation support strategy is a good idea in lung transplantation}

Anders Andreasson, MD, PhD, and Konrad Hoetzenecker, MD, PhD

Loor and colleagues ${ }^{1}$ addressed the still controversial issue of intraoperative mechanical circulatory support during lung transplantation (LTx). For this purpose, the authors performed a retrospective analysis of a registry initiated by 10 high-volume transplant centers. We would like to congratulate the authors for their enormous effort to shed further light on this important topic in clinical LTx.

Once more, this multicenter approach confirmed previous reports on the inferiority of cardiopulmonary bypass $(\mathrm{CPB})$ as the primary support device. ${ }^{2-6} \mathrm{CPB}$ is associated

\footnotetext{
From the Department of Thoracic Surgery, Medical University of Vienna, Vienna, Austria.

Disclosures: The authors reported no conflicts of interest.

The Journal policy requires editors and reviewers to disclose conflicts of interest and to decline handling or reviewing manuscripts for which they may have a conflict of interest. The editors and reviewers of this article have no conflicts of interest.

Received for publication Dec 3, 2021; revisions received Dec 3, 2021; accepted for publication Dec 3, 2021; available ahead of print Dec 8, 2021.

Address for reprints: Konrad Hoetzenecker, MD, PhD, Department of Thoracic Surgery, Medical University of Vienna, Waehringer Guertel 18-20, 1090 Vienna, Austria (E-mail: konrad.hoetzenecker@meduniwien.ac.at).

J Thorac Cardiovasc Surg 2022;164:1363-4

0022-5223/\$36.00

Copyright (C) 2021 by The American Association for Thoracic Surgery

https://doi.org/10.1016/j.jtcvs.2021.12.008
}

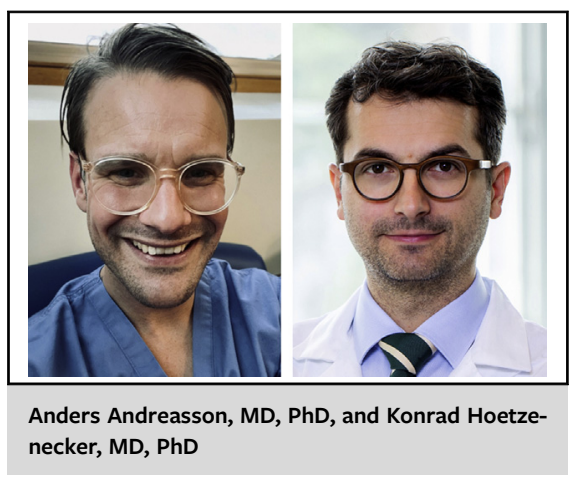

CENTRAL MESSAGE

A strategy of routine intraoperative VA ECMO use leads to extremely low rates of primary graft dysfunction and translates into improved survival compared with off-pump concepts.

with a higher risk of postoperative bleeding, a higher risk of severe primary graft dysfunction (PGD), higher risk for renal failure, longer intensive care unit and hospital stays. ${ }^{7}$ Based on this profound body of evidence, it is hardly justifiable anymore to cling onto CPB for mere intraoperative haemodynamic support during LTx.

However, the extracorporeal membrane oxygenation (ECMO) results presented by Loor and colleagues ${ }^{1}$ require a closer look. As acknowledged by the authors, this retrospective dataset is quite heterogenous and therefore difficult to interpret. Firstly, the study did not distinguish between routine or selective ECMO use. Secondly, study sites did not apply uniform indications for ECMO. Thirdly, the 